\title{
Kolorektal Kanseri Önleme: Kolorektal Kanser Risk Danışmanlı̆̆ı
}

\author{
Colorectal Cancer Prevention: Colorectal Cancer Risk Counseling
}

\author{
Şerife KOÇ
}

İletişim/ Correspondence: Şerife KOÇ Adres/ Adress: Karamanoğlu Mehmetbey Üniversitesi Sağlık Yüksekokulu, Hemşirelik Bölümü, Halk Sağlığı Hemşireliği AD., Yunus Emre Yerleşkesi70200, Karaman Tel: 03382262000 Fax: 03382262134 E-mail: serifenarr@hotmail.com

\section{$\ddot{O} Z$}

Kolorektal kanser tüm dünyada morbidite ve mortalite açısından önde gelen kanserlerden biridir. Kolorektal kanser mortalite ve morbiditesinin azaltılmasında bireyin risklerinin belirlenmesi ve buna uygun danışmanlık yapılması önemli bir yer tutmaktadır. Kolorektal kanser risk danışmanlığı bireye yönelik olarak hastalık hakkında farkındalık kazandırmak, bilgilendirmek, erken tanı testlerini yaptırmak izlemek amacıyla sürdürülen bir uygulamadır. Birinci basamakta yeterli eğitim almış halk să̆lı̆̆ hemşireleri, ikinci basamakta ise onkoloji hemşireleri tarafindan yürütülmektedir. Kolorektal kanser risk danışmanlığ etkin olarak uygulanmasıyla kolorektal kanserin önlenmesi ve kontrol altına alınması sağlanabilecektir. Bu derlemenin amacı hemşirelere kolorektal kanser risk danışmanlığı ile ilgili bilgi vermektir.

Anahtar Kelimeler: Kolorektal kanser, risk danışmanlığı, hemşire.

\section{ABSTRACT}

Colorectal cancer is one of the leading types of cancer around the world in terms of morbidity and mortality. Determining an individual's risks and providing appropriate counseling are important in reducing colorectal cancer mortality and morbidity rates. Individual colorectal cancer risk counseling is conducted to raise awareness about the disease, provide information, encourage and follow up on early diagnostic testing. This process is supervised by adequately trained public health nurses in primary healthcare and by oncology nurses in secondary healthcare centers. The colorectal cancer risk counseling process involves implementation, monitoring and evaluation. Establishing well-implemented counseling programs will contribute to preventing colorectal cancer and keeping the illness under control. The purpose of this review is to provide nurses information about colorectal cancer risk counseling.

Keywords: Colorectal cancer, risk counseling, nurse.

\section{GíRiş}

Kolorektal kanser (KRK) nedeniyle ölümler tüm kanser ölümleri arasında dünyada ikinci sırada yer almakta ve kanserden ölümlerin \%9-10'unu kapsamaktadır (Johnson ve ark. 2013; Tarraga, Albero ve Rodriguez 2014; Wilkes 2011). Kolorektal kanser en s1k görülen kanserler arasında erkeklerde üçüncü, kadınlarda ise ikinci sırada yer almaktadır (Ferlay ve ark. 2013). Türkiye'de ise en sık görülen ilk beş kanser türünden biridir (Gültekin ve Boztaş 2014).

Kolorektal kanser oluşumuna sebep olan birçok risk faktörü tanımlanmıştır. Bir insanın yaşam boyu KRK'ya yakalanma riski yaklaşık olarak \%5 civarındadır ve bu oran bireyin sahip olduğu risk faktörleri

\footnotetext{
${ }^{1}$ Arş. Gör. Karamanoğlu Mehmetbey Üniversitesi Sağllk Yüksekokulu Hemşirelik Bölümü, Karaman/ TURKEY
}

Yazının gönderilme tarihi: 25.05.2015

Yazının basım için kabul tarihi: 14.10.2016

doi: $10.17672 /$ fnhd. 95845 
ile ilişkili olarak değişmektedir (Çavdar 2015; Johnson ve ark. 2013; Price 2003; Sağlık Bakanlığı 2015; Türkiye Halk Sağlığı Kurumu 2013; Wilkes 2011). Kolorektal kanser risk faktörleri değiştirilemeyen ve değiştirilebilen faktörler olarak iki grupta incelenmektedir (American Cancer Society 2014; Chan ve Giovannucci 2010; Ertürk 2010).

Değiştirilemeyen risk faktörleri: Bireyin kontrol altına alamadığ 1 faktörlerdir. Yaş, cinsiyet, genetik, ülseratif kolit gibi kronik kolon hastalıkları, vb. değiştirilemeyen faktörlerdir (American Cancer Society 2014; Ertürk 2010).

Değiştirilebilen risk faktörleri: Kolorektal kanser riskini azaltmaya yardımcı olmak için müdahale edilebilen ya da yönetilebilen davranışsal faktörlerdir. Sigara kullanımı, alkol tüketimi, obezite ve dengesiz beslenme, kırmızı eti ve/veya işlenmiş et ürünlerini fazla tüketme, sedanter yaşam, vb. değiştirilebilen faktörlerdir (American Cancer Society 2014; Ertürk 2010; Glasper 2012; Tarraga ve ark. 2014;).

Değiştirilemeyen risk faktörlerinden "genetik" KRK oluşmasında önemli bir yer tutar; özellikle birinci ve ikinci derece akrabalarında KRK ve ülseratif kolit gibi kolon hastalıkları olanlar genel topluma göre yüksek risk altındadırlar ve bu durumda erken tanıya yönelik kolonoskopi taramaları önemli bir yer tutmaktadır (Çavdar 2015; Ertürk 2010).

Birçok kişi KRK risk faktörlerini bilmemektedir. Risk faktörlerini bilen bireylerin de korunma önlemlerini ve etkili girişimleri uygulamak için bir sağlık profesyoneli tarafından cesaretlendirilmesi ve desteklenmesi gerektiği belirtilmektedir. Risk faktörlerine uygun koruma stratejilerinin uygulanmasıyla KRK'nin yarıdan fazlasının önlenebileceği gösterilmiştir (American Cancer Society 2014; Glasper 2012). Ancak bu konuda bireylerin risk faktörlerine ilişkin olumsuz davranışlarının olumlu yönde değiştirilmesi, yüksek riskli bireylerin erken tanı için yönlendirilmesi ve davranış değişikliğinin uzun süreli olarak takip edilmesi gerekmektedir (Myers 2005; Price 2003).
Toplumda bireyler risklerinin farkında olmadan yaşamlarını sürdürmektedir. Sağlık profesyonellerinin farkındalığı artırmaya yönelik çalışmaları, risk değerlendirmesi yapması, kılavuzlara uygun önerilerle danışmanlık programları uygulaması ve olguları erken tanılayarak tedaviye yönlendirmesi ile KRK önlenmesi ve kontrol altına alınması mümkün olabilecektir (Sağlık Bakanlığı 2015; Koç ve Esin 2014). Bu nedenle KRK ile ilgili danışmanlık programlarının uygulanması önerilmektedir. Danışmanlık, sağlık ekibinin vazgeçilmez üyesi olan ve birey aile toplumla iletişim ve işbirliğini sağlayan hemşirelerin temel rollerinden biridir. $\mathrm{Bu}$ noktada KRK danışmanlığı konusunda yetiştirilmiş halk sağlığı hemşireleri bireylere erken dönemde ulaşarak risklerini kontrol altına almalarını sağlayabilir (Greenwald 2003; Greenwald 2005; Koç ve Esin 2014; Myers 2005; Price 2003).

Kolorektal kanser risk danışmanlığı yapabilmek için hemşirenin bu konu ile ilgili yetkin bilgi sahibi olması gerekir. Danışmanlık programları ve taramalar öncelikle riskli bireylere yönelik planlanmalıdır. Bu yüzden hem onkoloji hemşireleri hem de halk sağlığ hemşireleri KRK risk danışmanlığını yürütebilirler (Koç ve Esin 2014; Greenwald 2003; Greenwald 2005). Bu bağlamda bu derlemenin amacı, hemşirelere kolorektal kanser risk danışmanlığg ile ilgili bilgi vermektir.

\section{Kolorektal Kanser Görülme Sıklığı}

Kolorektal kanser tüm dünyada en sık görülen ikinci kanserdir. 2009 y1lı Türkiye Kanser İstatistikleri'ne göre; KRK Türkiye'de kadınlarda yüz binde 13.4 görülme sıklığı ile üçüncü, erkeklerde ise yüz binde 21,0 görülme sıklığı ile dördüncü en sık görülen kanser türüdür (Ferlay ve ark. 2013; Gültekin ve Boztaş 2014). Kolorektal kanser erken teşhis edildiğinde beş yıllık sağ kalım oranı \%90'a kadar çıkmaktadır. Birleşik veri tabanı (2009)'nında yer alan invaziv vakaların evreleri incelendiğinde, sadece \%29'unun lokalize olduğu, \%48.7'sinin ise bölgesel yayılımı olduğu görülmektedir (Gültekin ve Boztaş 2014). Ayrıca ülkemizde teşhis edilen KRK vakalarının yarısından çoğunun ileri evrede olduğu belirtilmektedir (Sağlık Bakanlığ 
2015). Bu oranlar KRK'nin erken tanı ve teşhis oranını yansıtmakta ve bu hastalığın erken teşhisinin ülkemizde istenen düzeyde olmadığını göstermektedir.

Kolorektal kanser mortalite ve morbiditesinde azalma sağlanması için her bireyin risk düzeyine göre erken tanı ve tarama yönteminin seçilmesi, risk davranışlarına yönelik olumlu davranış geliştirilmesi ve doğru aralıklarla takip edilmesi gerekmektedir (Ertürk 2010).

\section{Kolorektal Kanserden Korunma Stratejileri ve Tarama Kriterleri}

Dünya genelinde KRK'nin mortalitesini, morbiditesini azaltma ve kontrol altına almada üç düzeyli (primer, sekonder, tersiyer) bir önleme yaklaşımı ele alınmaktadır. Primer önlemler risk faktörlerine ilişkin yaşam biçimi değişiklikleri ve kemoprevansiyona odaklanır. Sekonder koruma önlemleri; "Kim nasıl taranmalı?" sorusunu cevaplamakta yani hangi testin kime, nas1 ve ne kadar aralıklarla uygulanacağı konusuna açıklık getirmektedir. Bu yüzden birçok ülkede KRK tarama önerileri/rehberleri oluşturulmuştur. Çalışma sonuçlarına ve teknik gelişmelere bağlı olarak tarama testleri ve izlem aralıkları sıklıkla güncellenerek uygulanmaktadır. Ülkelerarası farklılık gösterebilen bu öneriler tüm nüfusa aynı şekilde uygulanmamakta, bireylerin risk durumuna göre uygun testler önerilmektedir (Ertürk 2010; Mahon 2009; Levin ve ark. 2008; Price 2003). Çeşitli derneklerin konsensus çalışmaları sonucunda risk gruplarına göre tarama önerileri 2008 yılın- da yayınlanmıştır (Ertürk 2010; Levin ve ark. 2008). Türkiye'de Sağlık Bakanlığı tarafindan oluşturulan "Kolorektal Kanser Tarama Standartları" doğrultusunda ulusal tarama önerileri Tablo 1'de gösterilmiştir (Sağlık Bakanlığı 2012; Sağlık Bakanlığı 2015; Türkiye Halk Sağlığı Kurumu 2013). Ulusal standartlar ile uluslararası öneriler arasında bazı farklılıklar olmakla birlikte Türkiye'de yüksek riskli bireylerin tarama işlemlerinin ve takibinin hangi testlerle ve nerede yapılacağı ile ilgili belirsizlikler vardır. Her bir testin avantaj ve dezavantajları farklıdır ancak bireyin risk durumuna ve tercihine göre tek başına ya da birbirleriyle kombine olarak önerilebilirler.

\section{KOLOREKTAL KANSER RİSK DANIŞMANLIĞI}

Kolorektal kanser risk danışmanlığı, KRK'nin birincil ve ikincil düzeyde önlenmesi ile morbidite ve mortalite oranının azaltılmasını sağlar. Kolorektal kanser risk danışmanlığı, bireylerde KRK hakkında farkındalık oluşmasını, bireylerin KRK riskleri ve risklere ilişkin koruma önlemleri hakkında bilgilenmesini, primer ve sekonder koruma önerileri ile koruyucu sağlık davranışlarına ve tarama testlerine yönelmelerini amaçlayan ve birbirini izleyen kritik adımlardan oluşan bir süreçtir. Bu süreç; kapsamlı tanılama, kanser riskini ve genetik yatkınlığı belirleme, bilgilendirme, eğitim ve taramaya yönlendirme, genetik danışmanlık, risk yönetim planı oluşturma, planın izlemi ve değerlendirilmesini içerir. Risk danışmanlığında etkin sonuçlar

Tablo 1. Kanser Daire Başkanlığı Kolorektal Kanser Tarama Önerileri ve İzlem Sıklığı

\begin{tabular}{|c|c|c|c|}
\hline Risk Grubu, Yaş & Test & Öneriler & Yaş \\
\hline \multirow{2}{*}{$\begin{array}{l}\text { Ortalama Risk } \\
50-70 \text { yaş arası asemptomatik } \\
\text { bireyler }\end{array}$} & $\begin{array}{l}\text { Gaitada Gizli Kan Testi } \\
\text { (GGKT) }\end{array}$ & İki yılda bir & \multirow{2}{*}{$\begin{array}{l}50 \text { yaşından itibaren } \\
\text { (Son iki GGKT negatif olan } 70 \text { yaş ve üstü } \\
\text { bireylerde tarama sonlandırılır) }\end{array}$} \\
\hline & Kolonoskopi & 10 yılda bir & \\
\hline $\begin{array}{l}\text { Yüksek Risk } \\
\text { Birinci derece akrabalarında } \\
\text { kolorektal kanser veya adenomatöz } \\
\text { polip olan bireyler*, } \\
\text { Ülseratif kolit, Crohn hastalığı } \\
\text { ya da kalıtsal polipozis(HNPCC) } \\
\text { veya polipozis dışı sendrom (FAP) } \\
\text { öyküsü olan bireyler. }\end{array}$ & \multicolumn{2}{|c|}{$\begin{array}{l}\text { Tarama prosedürü olguyu takip eden } \\
\text { kliniklerce belirlenmelidir. }\end{array}$} & $\begin{array}{l}40 \text { yaşından itibaren, } \\
\text { *Birinci derece akrabalarında erken yaşta } \\
\text { kolorektal kanser ortaya çıkan bireylerde, } \\
\text { akrabalarında kanserin çıkış yaşından } 5 \text { yıl } \\
\text { önce başlanmalıdır. }\end{array}$ \\
\hline
\end{tabular}


elde etmek için; bireye özgü mesajlar verme ve risk durumunu bireyle birlikte değerlendirme, karar almada destekleme önemlidir. Ayrıca bireylerin tarama yaptırma durumunun izlenmesi, anormal test sonuçları olan bireylerin takibi ve yönlendirilmesi amaçlanır. Böylelikle KRK risk danışmanlığı tarama oranlarının artmasını ve KRK'nin erken evrede belirlenmesini ve KRK oluşmadan önlemeyi, morbidite ve mortaliteyi azaltmayı amaçlamaktadır (Koç 2014; MacDonald 1997; Nahcivan ve Seçginli 2015).

Risk danışmanlığında, risk tanılamasını yapan personelin ve risk danışmanının belli özelliklere sahip olması gerekir. Risk danışmanlığını uygulayacak personelin KRK ilgili yeterli ve güncel bilgi donanımına sahip olması, iletişı̇m tekniklerini, eğitim ve danışmanlık becerilerini iyi kullanabilmesi ve bazı özel becerilere sahip olması gerekir. Ayrıca eğitim ve danışmanlık için uygun, yeterli havalandırma ve ışıklandırma sistemine sahip bir danışmanlık odası olması gerekmektedir.

\section{Kolorektal Kanser Risk Danışmanlığı Aşamaları}

Kolorektal kanser risk danışmanlığı; bireysel eğitim ve danışmanlığ kapsar. Kolorektal kanser risk danışmanlığı üç aşamada uygulanabilir (Koç 2014; Koç ve Esin 2014):

1. Aşama: Uygulama aşaması

2. Aşama: İzlem aşaması

3. Aşama: Değerlendirme aşaması

Uygulama Aşaması: Uygulama aşaması farkındalık oluşturma, risk tanılaması ve bilgilendirme/eğitim olmak üzere üç bölümden oluşur.

Bireye hastalıkla ilgili detaylı bilgi aktarımı yapmadan önce farkındalık oluşturulmalı, bireyin dikkati o konuya yöneltilmeli ve soru sormasına izin verilmelidir (Koç 2014).

Farkındalık oluşturma; katılımcıların sağlığının korunmasında KRK'dan korunma davranışlarının önemi konusunda farkındalık kazanmaları amacıyla çeşitli girişimler kullanılabilir. Konuyla ilgili olarak yapılan çalışmalarda uygulanan ve önerilen kanıt temelli giri- şimler ve yöntemler Tablo 2'de gösterilmiştir (American Cancer Society 2014; Brouwers ve ark. 2011a; Brouwers ve ark. 2011b; Gimeno-Garcia ve ark. 2014; Rawl, Menon, Burness ve Breslau 2012; Sabatino ve ark. 2012). Bu girişimlerde bireyin korunma davranışlarını sergilemeye teşvik etmesi amaçlandığı için kullanılacak materyallerde (afiş, posterler vb.) KRK'den korunmanın mümkün olduğuna dair olumlu mesajlar vermek önemlidir (Greenwald 2003; Greenwald 2005; Price 2003).

Risk tanılaması; yapabilmek için yeterli sağlık öyküsü almak önemlidir. Danışmanlık sürecinde birey tanılama kapsamında bireyin;

- Demografik, sosyo-ekonomik, kültürel özellikleri ve tıbbi öyküsü (geçirilmiş/var olan hastalıklar; özellikle kronik bağırsak hastalıkları, polip varlığı vb.),

- Ayrıntılı aile öyküsü (özellikle birinci ve ikinci derece akrabalar),

- Bilişsel ve psikososyal durum (bilişsel kapasite, KRK bilgi düzeyi, risk algısı, KRK'ye ilişkin sağlık inançları ve tutumu, algıları, motivasyonu, endişeleri, engelleri, KRK ilgili deneyimler, anksiyete ve korkular, baş etme mekanizmaları ve sosyal destek durumu, karar alma ve karar destek sistemleri vb.)

- Yaşam biçimi davranışları (KRK riskini artıran alışkanlıklar, beslenme davranışı, fiziksel aktivite durumu, sigara ve alkol kullanımı, stres düzeyi, gibi olumsuz davranışlar ve sağlıklı yaşam biçimine verilen önem),

- Çevresel risk faktörlerine maruziyet ve diğer özelliklere ilişkin veriler toplanmalıdır.

Risk değerlendirmesi pratik risk değerlendirme araçları (risk hesaplama arac1, pedigramlar vb.) ve elektronik sağlık kayıtları kullanılarak yapılabilir (American Cancer Society 2014; Gimeno-Garcia ve ark 2014; MacDonald 1997; Nahcivan ve Seçginli 2015). Risk değerlendirmesinde elde edilen verilere göre bir risk derecelendirmesi yapılır. Risk derecelendirmesi, bireyin ne kadar riskli olduğunun belirlenmesi ve risk grubuna göre yönlendirme yapılmasıdır. Kanser risk 
derecesi bireylerin tarama testlerine yönlendirilmesinde önem taşımaktadır. Buna göre bireylerin "ortalama risk", "artmış risk" ve "yüksek risk" gruplarından hangi grupta olduğu belirlenir. Her risk grubundaki bireyler için tarama önerileri ve izlem aralıkları farklıdır (Ertürk 2010; Mahon 2009; Price 2003). Tablo 1'de görüldüğü gibi Türkiye' de kanser taramalarında “ortalama risk" grubundaki bireylerin 50 yaşında taramaya başlamaları gerekirken "artmış risk" ve "yüksek risk" grubundaki bireylerin 40 yaşında başlamaları önerilmektedir. Birinci derece akrabasında 40 yaşından daha önce KRK görülen bireylerin ise ailesinde KRK'nın görüldüğü yaştan 5 yaş önce taramaya başlamaları gerekmektedir. Benzer olarak, "ortalama risk" grubundaki bireylere yıllık GGKT ve 10 yılda bir kolonoskopi önerilmektedir ancak "artmış risk" ve "yüksek risk" grubundaki bireylere yapılan tarama testleri değişiklik gösterebilir ve izlem aralıkları daha sık takip edilmektedir. Eğer birey “yüksek risk" grubunda ise, ileri testler, genetik test ve danışmanlık için yönlendirilmesi gerekir (Ertürk 2010; Mahon 2009; Price 2003; Sağlık Bakanlığı 2012).

Kanser risk tanılamasının nasıl yapılacağ ve yorumlanacağ1 konusunda doğru ve tutarlı bilginin olması önemlidir. Bu konuda ulusal/uluslararası rehberler dikkate alınmalıdır. Risk değerlendirmede, web destekli araçlar ve matematiksel risk tanılama modelleri kullanılması riskin yorumlanması ve bireyin koruma önerilerine yönlendirilmesinde kolaylık sağlayabilir. Risk durumunu grafiklerle (çubuk, pasta, histogram) anlatmak riskin daha kolay anlaşılmasını sağlayacaktır (Ertürk 2010; Mahon 2009; Nahcivan ve Seçginli 2015).

Sağlık davranış modelleri insanların farklı sağlık davranışlarını neden uyguladıkları ya da uygulamadıklarını anlamak için geliştirilmiştir. Bireylerin korunma davranışını etkileyen faktörleri belirlemede ve olumsuz davranışlarını değiştirmelerinde danışmanlık yaparken sağlık davranış modelleri "kara kutu" görevi görür. Bu yüzden sağlı profesyonellerinin sistematik, kuram temelli sağlık davranış modellerini bilmesi ve bu modellerden yararlanması gerekir. $\mathrm{Bu}$ modeller arasında en çok kullanılanlar Sağlık İnanç Modeli, Koruyucu Sağlık Modeli, Transteoritik Model ve Sağlığı Geliştirme Modelidir (Gimeno-Garcia ve ark. 2014; Myers 2005; Price 2003).

Hastalı̆̆a özel yeterli bilgilendirme; bilgilendirmede hastalıkla ilgili bilgi eksikliğini gidermekve bireyi KRK tarama testlerine (gaitada gizli kan testi, kolonoskopi, çift kontrastlı bağırsak grafisi, sigmoidoskopi) yönlendirmek amaçlanmalıdır. Eğitim modülünde; kolon ve rektum anatomisi, sindirim sistemi, KRK oluşumu, KRK belirti ve bulguları, değiştirilemeyen ve değiştirilebilen risk faktörleri, hastalıktan korunmanın önemi, korunma yolları, sağlıklı yaşam biçimi davranışları, erken tanı ve tarama testleri, her bir testin avantaj ve dezavantajları, KRK korunma davranışları ile ilgili bilgiler verilmelidir (Gimeno-Garcia ve ark. 2014; Koç ve Esin 2014; MacDonald 1997; Mahon 2009; Price 2003).

Beslenme, obezite ve fiziksel inaktivitenin KRK ile ilişkisi kanıtlanmıştır (American Cancer Society 2014; Chan ve Giovannucci 2010; Wilkes 2011). Fiziksel aktivite düzeyi yüksek olan kişilerin minimal fiziksel aktivite düzeyindeki kişilere göre KRK'e yakalanma riski \%25 daha düşüktür (Wilkes 2011). Fiziksel aktivite ve sedanter yaşam, obezite ile de ilişkilidir. Fiziksel aktivite düzeyinin arttırılması, doğru beslenme, obezitenin azaltılması, sigaranın bırakılması ile KRK riskinin $\% 50$ oranında azalabileceği belirtilmektedir (American Cancer Society 2014; Wilkes 2011). Beslenmede kirmızı et yerine balık/tavuk, sebze meyve, tahıllı gidalar gibi lifli besinlerin tercih edilmesi adenom ve KRK riskini azaltmaktadır. Sigara kullanan bireylerde KRK oluşma riski, sigara kullanmayan bireylere göre 1.64 (rölatif risk) kat daha fazladır (Wilkes 2011).

Bireyin risk derecesine uygun tarama girişimlerini yaptırması sağlanmalı ve izlenmelidir (Tablo 1). Bireyin uygun tarama programına katılmasında ve KRK risklerinden korunmaya yönelik olumlu davranışlar1 kazanmasında, hastalıkla ilgili sağlık inançları oldukça önemlidir. Bu nedenle danışmanlık sırasında bireyin sağlık inançları, motivasyonu, engelleri çeşitli 
ölçeklerle belirlenebilir ve bu yönde eğitim verilebilir (Mahon 2009; Price 2003).

Eğitim bölümünde video gösterimi ve yazılı materyaller, sunum, motivasyonel görüşme, aktif dinleme gibi teknikler kullanılabilir. Taramayı teşvik eden materyaller; (küçük miktarda para, kupon, hediye çeki, vb.) ve bireysel özendiricilerin tek başına kullanıldığı çalışma yoktur bu yüzden bu girişimlere ilişkin kanıtlar yetersizdir. Eğitim sonunda eğitimin etkinliğini değerlendirmek amaciyla değerlendirme ve memnuniyet testleri uygulanabilir, tarama yaptırmayı isteyen bireyler ilgili birimlere ve polikliniklere yönlendirilmelidir.

İzlem aşaması: Bireyin farkındalığını sürdürme ve KRK korunma davranışlarını desteklemek amaçlanır. Hastalığa verilen önemi artıracak ve eğitim verilen konulara ilişkin davranışların tutarlılığını sağlayacak girişimler uygulanabilir. Uygulama aşamasından sonraki izlemler yüz yüze görüşme, telefon, e-posta gibi yöntemlerle yapılabilir (Tablo 2).

Bu girişimler sırasında; eğitimde verilen açık net kısa mesajlar tekrarlanarak bireyin bu mesajlara uyup uymad1- ğ1/katılıp katılmadığı sorgulanabilir. Örneğin; KRK'den korunmaya yönelik sağlıklı yaşam biçimi davranışları ve tarama önerileri yeniden tekrarlanabilir, olumsuz test sonuçları alındığında başvurulacak yerler ile ilgili bilgi verilebilir. $\mathrm{Bu}$ aşamada bireyin korunma davranışlarını sergilemesi ya da en azından bu davranışlara ilişkin istekliliğinin artması beklenir. Eğitimden sonraki sürede tarama testini yaptırıp yaptırmadığı, KRK korunmaya ilişkin sosyal destek alıp almadığı (aile, arkadaşlar, sağlik profesyonelleri) sorgulanabilir. Bu aşamada olumlu davranışlar desteklenir ve birey koruyucu davranışlar için cesaretlendirilir (Koç 2014; MacDonald 1997; Mahon 2009; Myers 2005; Price 2003).

Değerlendirme aşaması: $\mathrm{Bu}$ aşamada, bireyin KRK korunma davranışlarını sergileme durumu değerlendirilir. Kolorektal kanser risk danışmanlığında bireylerin bilişsel/psikososyal ve davranışsal becerilerinde olumlu yönde bir artış hedeflenmektedir. Bireylerde davranış değişimi, kısa sürede gerçekleşebilecek bir hedef değildir, uzun süreli takip ve izlem gerektirmektedir. Bireyin olumlu davranışa karar vermesi, davranış değişiminin gerçekleşmesi ve sürekliliğin sağlanması için

Tablo 2. Kolorektal Kanser Risk Danışmanlığının Tüm Aşamalarında Uygulanabilecek Kanıt Temelli Girişimler

\begin{tabular}{|c|c|c|}
\hline \multicolumn{3}{|c|}{ UYGULAMA AŞAMASI } \\
\hline Bölümler & Girişimler/Yöntemler & Araç-Gereçler \\
\hline $\begin{array}{l}\text { Farkındalık } \\
\text { Oluşturma }\end{array}$ & $\begin{array}{l}\text { Girişim: KRK risk faktörleri, korunma, erken tanı hakkında } \\
\text { bilgilendirme } \\
\text { Yöntem: Yüz yüze görüşme, telefonla görüşme, video/slayt } \\
\text { gösterimi, rol modeller ile tanıştırma, motivasyonel görüşme, } \\
\text { mektup yollama }\end{array}$ & $\begin{array}{l}\text { Afişler, posterler, maketler, TV ve gazete } \\
\text { reklamları, mektuplar, posta/ e-posta yoluyla } \\
\text { davet, telefon mesajları, takvimler, eşantiyon/ } \\
\text { promosyon gibi teşvik ediciler, tanıtım standı, } \\
\text { vb. }\end{array}$ \\
\hline Risk Tanılaması & $\begin{array}{l}\text { Girişim: Bireyin risk derecesini belirleme } \\
\text { Yöntem: Yüz yüze görüşme, bilgisayar destekli risk } \\
\text { tanılama modelleri }\end{array}$ & $\begin{array}{l}\text { Risk değerlendirme cetvelleri, soyağacı } \\
\text { çizelgesi, grafikler, histogramlar, elektronik } \\
\text { sağlık kayıtları }\end{array}$ \\
\hline $\begin{array}{l}\text { Hastalığa Özel } \\
\text { Bilgilendirme }\end{array}$ & $\begin{array}{l}\text { Girişim: Hastalıkla ilgili uygun ve yeterli bilgi verme } \\
\text { Yöntem: Yüz yüze görüşme }\end{array}$ & $\begin{array}{l}\text { Slaytlar, afişler, broşürler, eğitici videolar, } \\
\text { sağlık inanç ölçekleri, yazılı materyaller }\end{array}$ \\
\hline \multicolumn{3}{|c|}{ İZLEM AŞAMASI } \\
\hline & $\begin{array}{l}\text { Girişim: Farkındalığı sürdürme, olumlu davranışı } \\
\text { destekleme, tarama davranışını izleme } \\
\text { Yöntem: Görüşme }\end{array}$ & $\begin{array}{l}\text { Telefon görüşmesi, kısa mesaj, e-posta, } \\
\text { hatırlatıcılar, merkeze davet, ödül }\end{array}$ \\
\hline \multicolumn{3}{|c|}{ DEĞERLENDİRME AŞAMASI } \\
\hline & $\begin{array}{l}\text { Girişim: Koruyucu davranışı ve taramaya katılımı } \\
\text { değerlendirme, test sonuçlarını değerlendirme } \\
\text { Yöntem: Yüz yüze görüşme }\end{array}$ & $\begin{array}{l}\text { Otomatik telefon aramaları } \\
\text { Web tabanlı değerlendirme }\end{array}$ \\
\hline
\end{tabular}


risk danışmanlığının uygulanmasından sonra belirli aralıklarla (örneğin; 3., 6., 12., 24. aylarda) değerlendirme yapılmalıdır (Gimeno-Garcia ve ark. 2014; MacDonald 1997). Değerlendirme aşamasının, bireylerden geri bildirim alınmasına izin verdiği için genellikle yüz yüze olması önerilebilir. Değerlendirmede KRK'dan korunmaya yönelik beslenme davranışlarını sergileme durumu, fiziksel aktivitesinde artış olup olmadığı, program sonrası alkol sigara kullanımı, erken tanıtarama testlerini yaptırma durumu ve risk danışmanlığının etkinliği değerlendirilir. Tarama testi yaptırma durumunda, testin nerede, ne zaman yapıldığı, test sonuçları ile ilgili geribildirim alınır, olumsuz test sonuçları alınmışsa başvurulacak yerler ile ilgili yönlendirme yapılır. Birey program sonunda tarama yaptırmamışsa nedenler/engelleri belirlemek ve bu engellere ilişkin yeniden girişimler planlamak gerekmektedir (Koç 2014; Koç ve Esin 2014; MacDonald 1997; Mahon 2009; Myers 2005; Price 2003; Sabatino ve ark. 2012).

\section{SONUÇ VE ÖNERILER}

Kolorektal kanserin kontrolünde birincil ve ikincil koruma önlemleri birlikte yürütülmesi gereken uygulamalardır. Bireyin tek başına birincil önlemleri uygulaması yeterli olmayacağı gibi, birincil koruma önlemlerini uygulamayıp sadece tarama testlerini yaptırmak da hastalığın oluşumunu engellemeyecektir. Bu yüzden bu iki düzey koruma önlemlerinin uygulanmasında birinci basamak sağlık hizmetlerinde çalışan hekim ve hemşirelere önemli görevler düşmektedir.

Tüm sağlık bakım alanlarında tanı, tedavi, vb. girişimler süresince bireylerle en fazla karşılaşan ve iletişime geçen hemşireler, farklı nedenlerle sağlık bakım hizmeti almak için gelen bireylere KRK hakkında kolay anlaşılır bilgi içeren mesajlar vermede önemli bir konumdadır.

Kolorektal kanser risk danışmanlığı özel bilgi ve beceri sahibi olmayı gerektirir. $\mathrm{Bu}$ nedenle risk danışmanlığı yapacak hemşirelerin uygun eğitimi almış olması gereklidir. Kolorektal kanser risk danışmanlığı, uygulama izlem ve değerlendirme aşamalarını içeren ve sağlık hizmetlerinin tüm basamaklarında geçerli olan bir süreçtir. Sürecin her aşaması için önerilen birçok girişim ve yöntem ilgili araştırmalarla ortaya konmuştur. Özellikle cerrahi, onkoloji ve halk sağlığ başta olmak üzere tüm sağlık bakım alanlarında çalışan ve konu ile ilgili yeterli eğitim almış hemşirelerin KRK risk danışmanlığı uygulaması ile KRK sıklığı ve indisans1 azaltılabilir.

\section{KAYNAKLAR}

American Cancer Society (ACS) (2014). Colorectal Cancer Factsand Figures 2014-2016. American Cancer Society, Inc., http://www.cancer.org/acs/groups/content/documents/document/acspc-042280.pdf (30.08.2014).

Brouwers, C. M. ve ark. (2011a). Effective interventions to facilitate the uptake of breast, cervical and colorectal cancer screening: An implementation guideline. Implementation Science, 6(1): 112-112.

Brouwers, C. M. ve ark. (2011b). What implementation interventions increase cancer screenin grates? A systematic review. Implementation Science, 6(1): 111.

Chan, A. D., Giovannucci, E. D. (2010). Primary prevention of colorectal cancer. Gastroenterology, 138(6): 2029-2043.

Çavdar, İ. (2015). Kolon, rektum ve anal kanserler. Can, G. (Ed.). Onkoloji Hemşireliği. Nobel Tıp Kitabevleri, İstanbul, 707-717.

Ertürk, S. (2010). Kolorektal kanserler: Epidemiyoloji, etiyolojide rol oynayan etkenler, tarama ve kemoprevensiyon. Baykan, A., Zorluoğlu, A., Geçim, E., Terzi, C. (Ed.). Kolon ve Rektum Kanserleri. Seçil Ofset Matbaacılık ve Ambalaj Sanayi Ltd. Şti., İstanbul, 15-30.

Ferlay, J. ve ark. (2013). GLOBOCAN 2012: Estimated Cancer Incidence, Mortality and Prevalence Worldwide in 2012. International Agency for Research on Cancer, http://globocan.iarc.fr/Pages/ fact_sheets_population.aspx (30.08.2014).

Gimeno-Garcia, A. Z., Buylla, N. H. A., Nicolas-Perez, D., Quintero, E. (2014). Public awareness of colorectal cancer screening: Knowledge, attitudes, and interventions for increasing screening uptake. ISRN Oncology, 2014(1): 1-19.

Glasper, A. (2012). Can nurses help to promote earlier diagnosis of bowel cancer? British Journal of Nursing, 21(1): 50-51.

Greenwald, B. (2003). Health fairs: An avenue for colon health promotion in the community. Gastroenterology Nursing, 26(5): 191-194.

Greenwald, B. (2005). How to market colorectal cancer screening awareness and colonoscopy services. Gastroenterology Nursing, 28(5): 435-437.

Gültekin, M. ve Boztaş, G. (2014). Türkiye Kanser İstatistikleri 2009. Sağlık Bakanlığı Türkiye Halk Sağlığı Kurumu Kanser Daire Başkanlığı, 40-41, http://kanser.gov.tr/Dosya/ca istatistik/2009kanseraporu.pdf (30.08.2014). 
Johnson, C. M. ve ark. (2013). Meta-analyses of colorectal cancer risk factors. Cancer Causes Control, 24(6): 1207-1222.

Koç, S. ve Esin, M. N. (2014). Screening behaviors, health beliefs, and related factors of first-degree relatives of colorectal cancer patients with ongoing treatment in Turkey. Cancer Nursing, 37(6): 51-60.

Koç, Ş. (2014). Kolorektal kanser risk danışmanlığının riskli bireylerin birincil ve ikincil koruma davranışlarını geliştirmeye etkisi. Yayınlanmamış Doktora Tezi, İstanbul Üniversitesi Sağlık Bilimleri Enstitüsü, İstanbul.

Levin, B. ve ark. (2008). Screening and surveillance for the early detection of colorectal cancer and adenomatous polyps, 2008: A joint guideline from the American Cancer Society, The US Multisocietyt ask force on colorectal cancer, and the American College of Radiology. Gastroenterology, 134(5): 1570-1595.

MacDonald, D. J. (1997). The oncology nurse's role in cancer risk assessment and counseling. Seminars in Oncology Nursing, 13(2): 123-128.

Mahon, S. M. (2009). Prevention and screening of gastrointestinal cancers. Seminars in Oncology Nursing, 25(1): 15-31.

Myers, E. R. (2005). Decision counseling in cancer prevention and control. Health Psychology, 24(4): 71-77.

Nahcivan, N. ve Seçginli, S. (2015). Kanserde tarama ve erken tanı. Can, G. (Ed.). Onkoloji Hemşireliği. Nobel Tıp Kitabevleri, İstanbul, 41-58.
Price, A. S. (2003). Primary and secondary prevention of colorectal cancer. Gastroenterology Nursing, 26(2): 73-81.

Rawl, S. M., Menon, U., Burness, A., Breslau, E. S. (2012). Interventions to promote colorectal cancer screening: An integrative review. Nursing Outlook, 60(4): 172-181.

Sabatino, S. A. ve ark. (2012). Effectiveness of interventions to increase screening for breast, cervical, and colorectal cancers: Nine updated systematic reviews for the guide to community preventive services. American Journal of Preventive Medicine, 43(1): 97-118.

Sağlık Bakanlığı (2012). Kolorektal Kanser Tarama Programı Ulusal Standartları, http://thsk.gov.tr/tr/index.php/kanser-nedir/423kolorektal-kanser-taslak (07.12.2014).

Sağlık Bakanlığı (2015). Ulusal Kanser Kontrol Planı 2013-2018. http://www.iccpportal.org/sites/default/files/plans/Ulusal_Kanser_ Kontrol_Plani_2013_2018.pdf(25.05.2015).

Tarraga L. P. J., Albero, J. S., Rodriguez-Montes, J. A. (2014). Primary and secondary prevention of colorectal cancer. Clinical Medicine Insights: Gastroenterology, 7(2014): 33-46.

Türkiye Halk Sağlığı Kurumu (THSK) (2013). Kolorektal Kanser Taramaları, Türkiye Halk Sağlığı Kurumu, Kanser Daire Başkanlığı Değerlendirme Raporları, http://kanser.gov.tr/Dosya/BilgiDokumanlari/raporlar/kolorektal.pdf (30.08.2014).

Wilkes, G. M. (2011). Colon, rectal, and anal cancers. Yarbro, C. H., Wujcik, D., Gobel, B. H. (Eds.). Cancer Nursing Principles and Practice. 7th ed., Jones and Bartlett Publishers, LLC., Sudbury, 1205-1257. 
